\title{
Division of Nuclear Physics
}

\section{L. Green, Liverpool Chairman of the Division}

The formation of a Nuclear Physics Division was approved at the session of the EPS Council in Paris, February 1970. The proposal for the establishment of such a division grew out of discussions at a meeting called by W. Gentner at Heidelberg in July 1969 during the International Conference on Nuclear Reactions Induced by Heavy lons. It was felt that a division covering both nuclear structure physics and particle physics should be considered but subsequent talks with high-energy physicists led to proposals for two divisions, the Nuclear Physics Division covering nuclear structure physics, and a High Energy and Particle Physics Division. As with all the Divisions of the EPS the present organization is provisional.

The Interim Board of the Division first met in September 1970. Nuclear physics sections already exist within many of the National Societies and there are some close regional associations but, lacking the central cohesive influence of a CERN, contacts between the National Societies in the nuclear structure field are not very strong. It was felt that one of the important functions of the EPS Nuclear Physics Division should be to strengthen contacts between the national and regional nuclear physics groups. Accordingly the Interim Board of the Division was drawn up with representation, initially, on a national or regional basis. Many of the members have been nominated by their National Societies and the first meeting of the Board endorsed this structure although recent Council decisions on the membership of $\mathrm{Di}$ visional Boards will make the continuance of this structure of the Board more difficult.

\section{Work of the Division}

At this early stage the work of the Division is mainly concerned with conferences. Many regular national or regional meetings on nuclear structure already take place and the Board feels that there is a need for open topical conferences in Europe in which the specialized topic keeps the attendance to a reasonable size. One such conference sponsored by the Board was arranged by the Laboratori Nazionali di Legnaro at Padua on the structure of $1 \mathrm{f} 7 / 2$ nuclei. The need for Gordon type conferences in nuclear physics in Europe has been recognized for some time. The EPS has arranged to organize conferences of this general type in the form of Europhysics conferences, and the Nuclear Physics Division is seeking to stimulate the arrangement of conferences in this series. General conferences in the field of nuclear physics have grown very large in Europe and there is a feeling that, while such conferences are necessary the number of topics covered should be limited. Here the Nuclear Physics Division can probably best collaborate with IUPAP in coordinating European general conferences in nuclear physics.

The Division has no financial resources and so can only stimulate and cooperate with organizations such as the National Societies in the conference field. The members of the Divisional Board have discussed within their own national areas plans for topical and general conferences and at the next meeting of the Interim Board in the late summer of 1971 it is hoped that a programme can be agreed. Some proposals such as one from the French Physical Society for a conference on selected topics in the fields of fission, nuclear structure studied by means of heavy ions, and nuclear physics above $100 \mathrm{MeV}$ have already been formulated.

A responsibility placed on the Division by the EPS Conference Committee is the arrangement of the divisional sessions during the next EPS General Conference at Wiesbaden where three afternoon sessions are to be organized by the Division.

The Board would also like to encourage the better communication of information on activities in the nuclear structure field amongst the physics community. U. Schmidt-Rohr, Max Planck Institut, Postfach 1248, Heidelberg, Fed. Rep. of Germany, has been appointed coordinator for communications on nuclear physics to Europhysics News.

The present members of the Board are :

L. L. Green (Chairman) Liverpool

C. van der Leun (Secretary) Utrecht

N. Cindro

Zagreb

A. Corciovei

Mme H. Faraggi

I. Lovas

Th. Mayer-Kuckuk

O. B. Nielsen

S. G. Nilsson

R. Nordhagen

R. A. Ricci

A. Strzalkowski

Bucharest

Y. Talmi

Gif-sur-Yvette

Budapest

Bonn

Copenhagen

Lund

Blindern

Legnaro

Cracow

Rehovoth

\section{Meetings}

Notification of the following meetings has been received. The meetings announced are in addition to those advertised in previous issues of Europhysics News. Those organized by Divisions of the EPS are printed in bold type and boxed those sponsored by the EPS are printed In bold type; Europhysics Conferences (See Meetings Issue 2 (12 M) of Europhysics News) are marked by an $\Theta$ preceding the date. These announcements are repeated. For a full list of events see the latest Meetings Issue of Europhysics News. The information is listed in this order: Date, title, venue, contact for information.

\section{Conferences}

\section{1}

\section{4 - 17 September \\ Physics of Condensed Matter: Metals and Phase Transformations \\ Florence, Italy \\ G. Boato, Istituto di Fisica dell'Università, Viale Benedetto XV 5, I-16132 Genoa}

18 September onwards

Hollow-Cathode Discharges and their Applications Orsay, France

J.L. Delcroix, Plasma Physics Laboratory,

Faculty of Sciences, F-91 Orsay

\section{0 - 23 September}

2nd European Meeting on Ferroelectricity

Dijon, France

L. Godefroy, Laboratoire de Diélectriques Ferroélectriques, Faculté des Sciences, Boulevard Gabriel 6, F-21 Dijon 